\title{
Llengua i identitat en l'obra de Benvingut Oliver i Joan Baptista Perales
}

\author{
Language and identity in Benvingut Oliver and Joan Baptista Perales \\ work
}

\author{
Adrià MARTí-BAdia \\ amariba@alumni.uv.es \\ Universitat de València
}

\begin{abstract}
Resum: Aquest treball es proposa analitzar la reacció dels erudits valencians Benvingut Oliver i Joan Baptista Perales davant els postulats de la filologia romànica sobre el català en la segona meitat del segle xix. A més, tractem de relacionar la posició d'Oliver i Perales amb altres erudits i escriptors del moviment reinaixencista i amb la consciència de comunitat lingǘstica compartida amb catalans, balears i nord-catalans. A partir de la meitat del Vuitcents els romanistes germànics funden la filologia romànica i constaten que el català és el nom de la llengua pròpia dels territoris de llengua catalana, diferent de l'occità i sense res a veure amb el llemosí amb què era conegut des de principis del segle xvi. Aquests postulats respecte a la identitat $\mathrm{el}$ nom de la llengua catalana són ràpidament rebuts i acceptats a Catalunya; $i$ a les Illes Balears i a la Catalunya del Nord foren rebuts positivament amb molt poques excepcions. Però no així al País Valencià, on només una minoria d'erudits com Benvingut Oliver i Joan B. Perales -entre d'altres- va acceptar i divulgar aquests postulats.
\end{abstract}

Paraules clau: Segle XIX, Nom i identitat de la llengua catalana, Renaixença Valenciana, Benvingut Oliver, Joan Baptista Perales.

\begin{abstract}
This paper analyses the reaction of the Valencian scholars Benvingut Oliver and Joan Baptista Perales against postulates on the Catalan Romance philology in the middle of the nineteenth century. Moreover, this work tries to relate Oliver and Perales position with others scholars and writers of the Renaixença Valenciana movement and the awareness of linguistic community shared with Catalan speakers from Catalonia, the Balearic Islands and North Catalonia. From the middle of the nineteenth century the German romanists found the Romance philology. They established «Catalan» as the name of the language of the Catalan-speaking areas. Even this is different from Occitan and has nothing to do with Limousin, which was known by this name since the early sixteenth century. Regarding the identity and the name of the Catalan language, these assumptions are quickly received and assumed in Catalonia. Although in the Balearic Islands and North Catalonia they were received positively with very few exceptions. Whereas in Valencia, only a minority of scholars like Benvingut Oliver and Joan B. Perales -among others- accepted and disseminated these postulates.
\end{abstract}

Keywords: Nineteenth century, Name and identity of the Catalan language, Valencian Renaissance, Benvingut Oliver, Joan Baptista Perales.

DATA PRESENTACIÓ: 07/11/2015 ACCEPTACIÓ: 07/12/2015 · PUBLICACIÓ: 26/12/2015

SCRIPTA, Revista internacional de literatura i cultura medieval i moderna, núm. 6 / desembre 2015 / pp. 120 - 135 ISSN: 2340-4841 $\cdot$ doi:10.7203/SCRIPTA.6.7827 


\section{Introducció}

La identitat i el nom de la llengua catalana pren una considerable importància al segle XIX arreu dels territoris de parla catalana. En la primera meitat d'aquest segle naix la filologia romànica, que inaugura el filòleg alemany Friedrich Christian Diez, a partir dels estudis del qual la llengua catalana no deixà d'ésser presa en consideració pels romanistes (Badia i Margarit 1989: 7-8). Per a Diez, «català» és el nom de la llengua pròpia dels territoris de llengua catalana, diferent de l'occità i sense res a veure amb el llemosí amb què era conegut des de principis del segle xvi (Colón 1978).

Aquests postulats foren rebuts i ràpidament acceptats a Catalunya, de la mà d'erudits com Antoni de Bofarull i de Brocà, que l'1 d'agost de 1854 publica al Diario de Barcelona l'article «La lengua catalana», on dóna una visió del desenvolupament històric del català i el diferencia del «llemosí» de les terres occitanes. També fou molt important el treball de filòlegs com Manuel Milà i Fontanals, que el 1858 reeixí a desmuntar el «llemosinisme onomàstic», en denunciar el 1858 la impropietat d'aquesta denominació per a referir-se a la llengua catalana (Ferrando 2006: 213), gràcies a la lectura de l'obra del nordcatalà Francesc Cambouliu (Bernat i Baltrons 2010).

Així, amb la restauració dels Jocs Florals de Barcelona el 1859, els catalans erigien una plataforma que els permetia prescindir del tradicional llemosinisme onomàstic pel fet que ja disposava d'uns referents propis, nacionals i nacionalitzadors (Rafanell 1991: 35-36). Amb l'acceptació dels postulats de la filologia romànica, els catalans veuen satisfetes les seues aspiracions identitàries -primer amb el Romanticisme i després amb la Renaixença-, ja que amb el nom de llengua catalana convergeixen el gentilici -catalans-, el nom del territori -Catalunya-i el nom de la llengua -catalana.

Tanmateix, aquests postulats filològics van xocar amb els sentiments identitaris de la majoria d'escriptors i erudits valencians, entre els quals «no hi hagué cap plantejament de la identitat valenciana que no fos alhora espanyol» (Archilés 2007: 510). La identitat regional valenciana, doncs, s'hi identificava de ple amb la identitat nacional espanyola, «fins al punt que podem afirmar que els valencians (d'altra banda com la resta de regions espanyoles) eren tant més espanyols com més valencians» (Archilés 2007: 517).

Així, «quan els intel lectuals del Principat començaren a impugnar l'abstrusa teoria llemosinista, els felibres valencians adoptaren sobtadament una actitud recelosa i defensiva» (Cucó 1999: 46), i el llemosinisme onomàstic pervisqué més temps que a la resta de territoris de llengua catalana. Aquest és el context en què es situa la vida i l'obra de Benvingut Oliver i Estellés i Joan Baptista Perales i Boluda.

L'objectiu d'aquest treball és, doncs, examinar la reacció de Benvingut Oliver i de Joan B. Perales davant els postulats de la filologia romànica sobre el català, amb especial atenció a l'origen, el nom i la identitat del català del País Valencià. A més, tractem de relacionar la seua posició amb la d'altres erudits i escriptors amb què va coincidir i divergir, així com amb la consciència de 
comunitat lingüística compartida amb catalans, balears i nord-catalans. Per a realitzar aquest estudi hem analitzat el conjunt de la seua obra i hem seleccionat aquells articles i llibres relacionats amb l'objecte d'estudi esmentat.

\section{Posició minoritària al País Valencià}

Com veurem, els exemples de lletraferits i erudits valencians que van adoptar el nom de català per al conjunt de la llengua, seguint així els postulats de la filologia romànica van ser escassos, i generalment s'expliquen perquè no residien al País Valencià o perquè s'expressen així fora de l'àmbit valencià.

En aquest context s'explica que la posició d'anomenar explícitament catalana el conjunt de la llengua, en consonància amb els postulats de la incipient filologia romànica, fou minoritària. Sabem que fou compartida -almenys- per quatre literats i erudits valencians. És el cas del poeta Vicent V. Querol i de l'escriptor Josep Maria Puig i Torralva -en la seua joventut. I, ja fora del moviment renaixencista valencià, és el cas de l'erudit Benvingut Oliver i Estellés i de l'escriptor en castellà Joan Baptista Perales, ambdós residents a Madrid.

\subsection{Benvingut Oliver i Estellés}

\subsubsection{Nota biogràfica}

Nat l'any 1836 a Catarroja, estudia el batxillerat a les Escoles Pies de València i queda orfe pel còlera que el 1854 assetjava el Cap i Casal. El 1856 es llicencia en Filosofia i Lletres, el 1858 en Dret i el 1859 es doctora -també en Dret- a la Universitat de València, i amb 24 anys comença a impartir classes a la Facultat de Dret. L'any 1862 és nomenat vocal de la Junta Directiva de l'Acadèmia Valenciana de Legislació i Jurisprudència, encara que més tard trasllada temporalment la seua residència a Barcelona, on l'any 1863 és nomenat sots-secretari de l'Audiència Territorial de Barcelona i un any després acadèmic de la Reial Acadèmia de Bones Lletres de Barcelona. Ací coneix a una jove Carmen Roman Diaz, amb qui contrau matrimoni l'any 1867 i es traslladen a viure l'illa antillana de Puerto Rico, d'on ella era originària. En aquest període exerceix l'advocacia i col labora amb el diari Las Provincias, on publica articles que descriuen la societat i l'administració porto-riquenya.

El 1870 s’instal la a Madrid, on obté la plaça de lletrat de la Direcció General del Registre de la Propietat i del Notariat. El 1874 és nomenat Subdirector General dels Registres i del Notariat i finalment- el 1899 Director General, càrrec que va mantenir fins a l'any 1901, amb l'entrada del Partit Liberal de Práxedes Mateo Sagasta al govern de l'Estat. Paral lelament, el 1870 és nomenat acadèmic corresponent de la Real Academia de la Historia, més tard -l'any 1881- és elegit acadèmic 
de número i l'any 1884 pren possessió de la medalla 13 de l'esmentada institució, acte en què pronuncia el discurs d'ingrés titulat La nación y la realeza en los estados de la Corona de Aragón durante la dinastía Barcelonesa. A més, amb la creació de la Insitución Libre de Enseñaña -l'any 1876 a Madrid- és nomenat professor d'aquesta, on imparteix les assignatures de dret penal i dret civil foral.

Segons Fuster (1982: 37), Oliver «era un home de Las Provincias», en el sentit que «devia ser "canovista", o "silvelista"», i ell i Teodor Llorente «van ser amics des de joves [com] sembla demostrar-ho el to de les cartes» entre ambdós recollides als volums II i III de l'epistolari llorentí (Fuster 1979: 162). L'erudit de Catarroja, fou traspassat a Madrid l'any 1912 a l'edat de 76 anys.

\subsubsection{El català de València en la seua obra}

Fou un dels iniciadors de la investigació erudita sobre el nostre passat jurídic i el primer en emprar la fórmula «països catalans» -en minúscula- (Fuster 1979: 160-161). Publica estudis de dret foral com Estudios históricos sobre el derecho civil de Cataluña (1867) i Historia del derecho en Cataluña, Mallorca y Valencia: código de las costumbres de Tortosa (1876-81), que -a més- conté l'edició crítica del Llibre de costums de Tortosa. Edita i publica els onze volums de l'obra Cortes de los antiguos reinos de Aragón y de Valencia y Principado de Cataluña, que són publicats a Madrid entre 1896 -el primer volum-i 1912 -el darrer, amb la col laboració dels catalans Víctor Balaguer i Fidel Fita.

Malgrat que no se li coneix cap text en català, és el primer valencià en emprar el nom «català» per a referir-se al conjunt de la llengua catalana. És el 1876 amb la publicació del primer volum de l'obra Historia del derecho en Cataluña, Mallorca y Valencia, en la qual realitza alguns comentaris sobre la llengua. A la introducció d'aquest primer volum, afirma que

entre los habitantes de los territorios conocidos con los antiguos nombres de Principado de
Cataluña y Reinos de Mallorca y de Valencia (...) todavía mantienen como vínculo de union la
misma lengua de orígen ó de nacimiento, á la cual designaremos con el nombre común y mas
propio de lengua catalana.
Este hecho que, si no somos los primeros en descubrir, nadie hasta ahora lo ha proclamado,
arroja inesperada luz sobre toda nuestra historia y sobre el verdadero carácter de los pueblos
que podemos llamar de lengua catalana, los cuales / aparecen á nuestros ojos partes de un
todo, como miembros de una nacionalidad, no sólo dentro de la gran familia española sino
dentro de aquel poderoso Estado político, conocido durante la Edad Media, y hasta el siglo
pasado, con el nombre de Corona de Aragon. (Oliver 1876: V-VI)

És una nítida manifestació de la recuperació de la consciència de comunitat lingüística compartida amb catalans, balears i nord-catalans. I l'erudit Oliver és sabedor que -com a valencià- expressava una qüestió important que al País Valencià estava passant desapercebuda. Dues pàgines més endavant insisteix respecte a la llengua dels territoris de parla catalana:

en una palabra, que todos esos pueblos, que como sello exterior é indeleble se valen de una misma lengua para expresar sus sentimientos y sus ideas, desde los Pirineos al rio Segura, y de las Islas del Mediterráneo, formaban y constituian una verdadera nacionalidad. (1876: IX) 
I poc després es refereix a la zona catalanoparlant del País Valencià amb el sintagma «los pueblos de lengua catalana del Reino de Valencia» (1876: XI).

Anys després, concretament el 1881, publica el quart i últim volum d'aquesta obra, que és una edició del Libre de les costums generals escrites de la insigne ciutat de Tortosa de 1539. Als preliminars, detalla aspectes filològics i lingüístics de l'obra i es refereix a la llengua del segle XIII amb els sintagmes «antiquisimo catalan» (1881: VI) i «catalan tan antiguo» (1881: VII), i també es refereix als «Diccionarios de lengua catalana» (1881: xx). Segons Marcet i Solà (1998: 1162), l’autor té plena consciència del que representa aquesta obra per a les terres de parla catalana. Més endavant afirma que

para exponer con claridad y método el contenido de sus preceptos y el espíritu de todas las instituciones jurídicas ordenadas en el mismo, nos ha sido forzoso hacer un prévio estudio analógico, ortográfico y sintáxico [sic] de ese mismo texto, á fin de conocer la verdadera significacion gramatical y lógica de las voces y de las frases (...). Mas al adoptar este sistema (...) conservamos (...) todos los elementos necesarios para que el gramático y el filólogo puedan estudiar el desarrollo de la lengua catalana (1881: X-XI).

D'altra banda, l'erudit Oliver fa referència a l'origen de la llengua catalana -encara que de manera indirecta- quan afirma que ha conservat la lletra ç «por considerarla como letra característica de la lengua de Oc y de sus variedades galo-meridional, provenzal y catalana» (1881: XIII). Més endavant empra un sintagma semblant: «nuestra edicion de las COSTUMs no está destinada exclusivamente á personas más ó menos familiarizadas con las variedades de la lengua de Oc» (1881: xx). I també realitza una referència semblant quan al ludeix a «los estudiosos dialectológicos romanos ó neolatinos, y en especial los que versan sobre las variedades de la lengua de Oc» (1881: XxII).

En referència al text editat -el Llibre de costums de Tortosa- afirma que està redactat en «idioma catalan antiquisimo» $\mathrm{i}$ lamenta el retard dels estudis

de nuestro Derecho nacional, y los dialectológicos; y sobre todo, la falta, cada vez más sentida, de una Academia regional de la lengua popular de Cataluña, Mallorca y Valencia, que estudiándola fundamentalmente y estableciendo los principios de su Morfología y Sintaxis, pueda restituir á este idioma su carácter y fisonomía propios y nativos. (1881: xx)

En termes filològics, l'edició d'aquest text «lo creemos muy distante de la perfeccion, y sus defectos los pondrá de manifiesto el estudio filológico de la lengua catalana» (Oliver 1881: xx). De totes formes, el vocabulari resultant d'aquesta edició «prestará alguna utilidad en los momentos actuales, y (...) siempre podrá recurrirse á él como un inventario de la lengua catalana del siglo XIII» (1881: XXI), perquè «corresponde á un período fijo y determinado de la lengua catalana» (1881: XXI).

Posteriorment aclareix els dubtes respecte a l'entitat de la llengua catalana que havia pogut crear adés i afirma nítidament la independència de la llengua catalana a l'hora d'afirmar que «La filología com- / parada de las lenguas formadas del latin al comenzar la Edad Media, y del castellano, provenzal, y catalan [sic] particularmente, acrecentarán el gran caudal de sus materiales» (1881: XXIIXXIII). I quan es refereix al Llibre de Costums com 


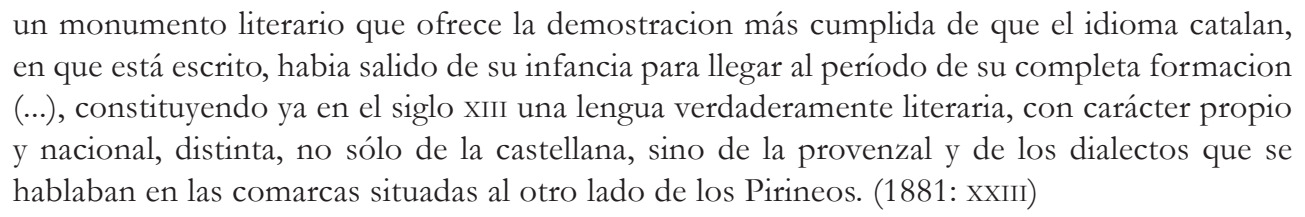

És a dir, Oliver afirma l'entitat independent de la llengua catalana, en igualtat de condicions amb altres llengües com el castellà i l'occità, encara que planteja algun dubte respecte a l'origen independent $-\mathrm{i}$ deslligat- de la llengua occitana. Ja ho havia explicat nítidament l'historiador nordcatalà Francesc Cambouliu (Palaldà, Vallespir, 1820 / Montpeller, 1869) l'any 1857 amb la publicació de l'Essai sur l'histoire de la littérature catalane. En aquest assaig -com afirma Bernat i Baltrons (2010: 88)-Cambouliu defensa que la llengua escrita pels trobadors catalans mai no havia estat la mateixa que parlaven els catalans, perquè aquesta era un codi lingüístic creat i reservat per al conreu de la lírica. I demostra que l'ús del terme «llemosí» per a la llengua dels trobadors havia nascut arran del prestigi que van tindre Las razós de trobar de Ramon Vidal de Besalú, autor que havia ampliat el sentit original del gentilici com a resultat de l'admiració que sentia per Bertran de Born i Giraut de Borneil, dos dels primers grans trobadors, ambdós originaris de la regió de Llemotges. Al cap i a la fi, l'ús del terme «llemosí» per a designar la llengua catalana venia creant confusions des de l'època medieval (Colón 1978).

\subsection{Joan Baptista Perales i Boluda}

\subsubsection{Nota biogràfica}

Fill d'Agostina Boluda i del mestre d'obres Mariano Perales, naix circumstancialment a Moixent l'any 1837 -on la seua família tenia béns. Residien a Xàtiva, on Perales passa la seua infantesa, encara que per circumstàncies familiars es trasllada en la seua joventut -primer- a València i -després-a Madrid. Treballa d'administratiu al Ministeri d'Hisenda i es llicencia en Filosofia i Lletres a Madrid, on arriba a exercir de professor al Seminari Escuelas Pías de San Fernando.

Com a periodista, treballa a la redacció d'El Mercantil Valenciano i arriba a ocupar un lloc distingit en la premsa madrilenya, amb el treball de redactor de La Gaceta Popular (1873) i amb la col laboració en revistes i periòdics literaris com La Ilustración Católica (1877) i La Niñez. (1879-1883), entre d'altres. Soci de la Reial Societat Econòmica d'Amics del País de València, l'any 1877 presenta una sol licitud per a treballar d'oficial en la secretaria d'aquesta entitat, però no se li concedeix. Trasllada la seua residència a València l'any 1883 i dirigeix La Correspondencia de Valencia fins que es trasllada -ja definitivament-a Barcelona l'any 1888. A Barcelona col labora amb les revistes Barcelona Cómica (1894-1896), El Gato Negro (1897-1898), Pluma y Lápir. (1902) i Hojas Selectas (1903), i treballa de redactor en cap del diari en castellà El Noticiero Universal des de la seua fundació (1888) fins al seu traspàs l'any 1904. 
Com a escriptor, publica a Madrid -i en castellà- Francia y Prusia. Crónica de la guerra de 1870 (18701871, en 3 vol.) i la sarsuela El Marino (1872); i estrena a València els drames teatrals -en castellàLa traición (1873) i Poesía eléctrica (1873). Publica a València les novel les històriques -també en castellà-Mariola (1878), Los Caballeros de Játiva (1878) i -la segona part- Los héroes de Montesa (1878).

Cal descatar, però, la seua obra com a cronista. S’inicia amb l'edició, anotació i continuació de les Décadas (1610-1611) de l'historiador valencià Gaspar Escolano, publicades en tres volums amb el títol Historia general del reino de Valencia els anys 1878, 1879 i 1880, respectivament. I més tard publica Tradiciones españolas. Valencia y su provincia (1882) i Las Germanías de Valencia (1886), entre d'altres. Va morir a Barcelona l'any 1904 a l'edat de 67 anys.

\subsubsection{El català de València en la seua obra}

Periodista i cronista, Joan Baptista Perales és valencià que s'interessa pel passat històric del poble valencià amb l'escriptura rigorosa de novel les i de cròniques històriques. Malgrat que no es coneix cap publicació en català escrita per ell, la seua obra és interessant -sobretot- per l'edició, anotació i publicació de les Décadas d'Escolano. Particularment ens interessa el tercer i últim volum que, com s’indica en la portada, és la «continuacion de las Decadas que escribió (...) Gaspar Escolano».

Aquest volum té un capítol titulat «Formación de la lengua valenciana» (1880: 53-54), en el qual Perales comença enumerant les llengües que hi ha als territoris de la corona d'Aragó en temps del rei Jaume I:

En los estados de don Jaime se habla el hebreo, el árabe, el latin, catalan, provenzal y aragonés, a más de la lengua de los poetas, y otras convencionales como la aljamia de los moros, y algun otro dialecto local. Pero parece, no obstante, que la lengua de los condes cultivada en Cataluña, es la mas generalizada y la que se sobrepone á todas, porque Barcelona que llenaba el mundo con su nombre debia llenarle tambien con los sonidos de su idioma. (1880: 53)

Tot seguit, Perales realitza una contundent afirmació respecte al nom del conjunt de la llengua catalana:

Sin desconocer, pues, su orígen ni antigua procedencia, la lengua de don Jaime, llámese de Oc, lemosina ó de Provenza, ha sido reformada en la corte de Barcelona y ya no puede llamarse sino catalana, que los catalanes la crearon y ellos han de difundirla con el pabellon de sus naves en los diversis estados de la costa del Mediterráneo. Esta es la lengua que habla don Jaime, y en la que ha de inmortalizar su nombre y sus obras. Y pues era su lengua natural en la que hablaba y escribia y las [sic] generalizada en sus estados [territoris], no habia de buscar otra para establecerla en Valencia, sino la catalana, admitida tambien en el reino de Mallorca. (1880: 53)

Com indica Rafanell (1991: 44), cal destacar la contundència d'aquestes paraules, que situa Perales com un dels primers valencians de la segona meitat del XIX a dir clarament que s'ha d'anomenar llengua catalana a la llengua de l'antic regne de València, sense circumloquis accessoris. Un fet important que ha passat per ull als estudiosos del període, incloent l'escriptor Constantí Llombart (València, 1848 / València, 1893), el qual evità qualsevol comentari al respecte en els seus «apunts 
bio-bibliográfichs» quan afirma que Perales -en el text esmentat- simplement presenta «l'orige y desemvolpament [sic] de la llengua llemosina» (1879: 540).

Tanmateix, Perales es confon quan es refereix a l'origen de la llengua catalana. Una confusió estesa entre els erudits del conjunt dels territoris de parla catalana, com hem observat adés amb el cas de l'erudit Benvingut Oliver.

Més endavant, Perales afirma que els historiadors coetanis

Creen (...) descubrir en el rey don Jaime el proyecto de establecer una lengua nacional en todos sus estados. Nada mas natural que así lo concibiese, y al abrigar semejante proyecto optase por la lengua lemosina ó catalana, no solo porque era su idioma nativo, sino porque era la mas extendida y usual y la mas familiar á los pueblos latinos. Pero no creemos, sin embargo, que don Jaime tratara de establecerla en el reino de Aragon, porque al redactar los fueros de Huesca, pudo haber intentado escribirlos en lengua catalana, y y [sic] nada revela esta intencion si la hubo, porque los fueros se escribieron en lengua aragonesa. Las naves y los guerreros conquistadores de Mallorca, procedieron en su mayor parte de Cataluña, y los marinos y los guerreros dejaron allí establecida su lengua que era la que hablaba y escribia su rey. Los aragoneses á / quienes era muy familiar aquella lengua por su contacto y correspondencia con Cataluña y el Rosellon, no debian oponerse al lenguaje allí establecido por el mayor número de pobladores catalanes. Iguales causas concurrieron en el reino de Valencia. (1880: 53)

I tot seguit diu clarament la seua opinió respecte el repoblament del regne de València produït amb la conquesta de Jaume I:

A la gran preponderancia que sobre la lengua aragonesa tenia la catalana, añadíase la circunstancia del gran número de gentes que aquí fluyeron procedentes de Cataluña, de la Provenza y de otros paises, y aunque no era escaso el número de los aragoneses, parece indudable que todo aquel conjunto de gentes estrañas entre sí necesitaban expresarse en una lengua comun á todos, y no había otra más general que la catalana, la que aparte de su preponderancia y de ser la lengua oficial porque era la del rey, era tambien la mas comprensible entre franceses, é italianos, y los españoles de diversas regiones y de todos aquellos pueblos de orígen latino. Conquistada Valencia se hablarian en ella tantas lenguas cuantos fueren los países de donde procedian las familias heredadas en la ciudad: pero se sobrepuso á todas la que era mas general, mas comprensible y mas culta á mas de ser la lengua del Conquistador, de los poetas y de los marinos, elemenos los mas eficaces para transportar las lenguas vivas á remotas playas é ignotos paises. 1880: 53)

Perales continua i tracta d'argumentar com s'establí la llengua catalana al regne de València, quan afirma que:

Estas son las primeras causas que concurrieron á la formacion de la lengua que debia perpetuarse en este reino. Siendo tantas las familias de catalanes y provenzales que quedaron heredadas en Valencia, predominó su lengua natural sobre la aragonesa, mezcla entónces de castellano y de lemosin, y sobre la fabla de Castilla por el menor número de familias de aquella nacion establecidas en Valencia. Nada indica por otra parte que tratasen los aragoneses de arraigar su lengua en este reino, porque guardaba tal afinidad con el lemosin, les era tan familiar este lenguaje, y han demostrado siempre tal facilidad para hablarle, que lejos de oponerse á que se adoptase la lengua catalana, debieron ser ellos de los primeros propagadores. Habíanse adoptado tambien por legítimo derecho las pesas y las medidas de Lérida, habian venido 
de aquella ciudad los siete primeros matrimonios establecidos en Valencia y con ellos las trescientas doncellas que casadas convenientemente con los soldados de la conquista, debian formar la base de la poblacion valenciana y establecer forzosamente su lengua materna. (1880: 53)

Al capdavall, segons Perales

Tampoco podia fijarse en Valencia otra lengua que no fuese la catalana. Pues si en tierra de Teruel se perpetuó la lengua aragonesa, fué porque era aragonés el rey don Alfonso, Conquistador de aquel territorio, y aragoneses los / caballeros y las familias que allí se establecieron como primeros pobladores. No estaba aun tan extendida por aquel tiempo la lengua provenzal ${ }^{1}$ que pudiera adoptarse en las conquistas de Aragon como lo estaba en tiempo de don Jaime en que aquella lengua alcanzó todo su apogeo, cultivada y protegida en la corte de los condes de Barcelona, de donde pasó mas tarde á Mallorca, Valencia, Sicilia y despues á Nápoles. Esta fué la época de los trovadores entre los que se citan no pocos caballeros que pulsaban la lira del poeta mientras permanecía ociosa su espada. De aquí nació el renombre y la popularidad de de aquella poesía cultivada en todos los países y cuya concisa, filosófica y espresiva lengua era la que debia imperar definitivamente en todo el reino de Valencia (I) ${ }^{2}$. Pero era ya desde la rendicion de la ciudad la lengua pública y general, la que compartia su dominio con el latin en los documentos oficiales, y la que debia sobreponerse con el tiempo fuera de los actos ó instrumentos religiosos que pertenecen exclusivamente á la Iglesia. (1880: 53-54)

Finalment, Perales conclou el capítol reafirmant de manera contundent que la llengua que es parlava al regne de València del segle XII era catalana. Perales fa constar

bajo la fé de los autores que en la materia nos han precedido, que los Fueros de Valencia fueron redactados en latin y traducidos despues á la lengua usual catalana que era la que se hablaba en Valencia. (...) Sea cual fuere no obstante, el punto de vista con que se examine esta obra, siempre resulta que por ser la primera que se escribió en Valencia, merece ser considerada con gran respeto, no solo por su mérito legislativo, sino tambien porque conserva intacto el lenguage que hablaron nuestros mayores en los primeros tiempos posteriores á la conquista. (...) y nos fija con rigurosa exactitud, los giros, el carácter, el espíritu del lenguaje que sirvió de matriz á la lengua valenciana. Ligeras modificaciones introducidas con el tiempo (...) variaron la forma de aquella antigua lengua, que aunque distinta en la parte indicada, en el fondo quedó siempre la misma. (Perales 1880: 54)

Així, l'erudit valencià no matisa la contundent afirmació, si no que la corrobora. La posició d'Oliver i de Perales respecte al nom del conjunt de la llengua catalana, com veurem tot seguit, no és aillada. També cal tindre en compte que -a més de València- visqué a Madrid i a Barcelona, i no sembla estar especialment vinculat a l'entitat valenciana Lo Rat Penat, on aquesta posició era minoritària.

1 Ací Perales no es refereix a la llengua «provenzal» si no a la llengua catalana. Perales torna a confondre's, doncs, referint-se a la llengua catalana del segle XII amb el mot «provenzal».

2 [Nota de Perales] Comarcas hay todavía en Valencia donde no se habla el valenciano, como en Énguera y algunos pueblos de su partido. De Castilla vinieron los pobladores de este territorio, y su lengua, inculta como era entónces y degenerada con la comunicacion y contagio de los valencianos, resulta hoy un dialecto aparte derivado de ambas lenguas y cuyo acento es dificil de precisar si oirlo de viva voz. Las comarcas que se aproximan á Teruel, desde Segorbe y Chelva en adelante, hablan tambien un castellano incorrecto, cuyo orígen debe buscarse en la lengua importada por los aragoneses. Lo mismo sucede en la provincia de Castellon y en la de Alicante: en esta última se adoptó el habla castellana en los pueblos fronterizos al reino de Murcia. 


\subsection{Vicent V. Querol i Josep Maria Puig i Torralva}

Al contrari que Benvingut Oliver i Joan B. Perales, el poeta Vicent Venceslau Querol i Campos (València 1837 / Bétera, 1889) i l'escriptor Josep Maria Puig i Torralva (València, 1854 / València, 1911) tenen una relació vital més llarga i directa amb la ciutat de València -i amb l'entitat Lo Rat Penat- epicentre de la Renaixença Valenciana i del llemosinisme.

\subsubsection{Vicent Venceslau Querol i Campos}

Es relaciona des de ben jove amb la creació poètica en llengua catalana -i amb la castellana-, així com amb els cercles inicials de l'esmentat moviment literari. L'any 1852 funda la societat literària La Estrella -entre d'altres-amb el cronista Fèlix Pizcueta i Gallel (València, 1837 / València, 1890), entitat que l'any 1858 passa a formar part del renovat Liceu de València. A l'etapa universitària coneix un jove Teodor Llorente i Olivares (València, 1836 / València, 1911) i comença a publicar poesies -en català i en castellà- a revistes valencianes com El Pensamiento de Valencia, El Miguelete i El Conciliador, entre d'altres. Coneix el poeta mallorquí Marià Aguiló (Palma, 1825 / Barcelona, 1897) amb l'arribada d'aquest a la biblioteca de la Universitat de València (1858-1861), i participa en l'organització dels primers Jocs Florals de València (1859). El 1868 assisteix als x Jocs Florals de Barcelona amb els poetes Llorente, Rafael Ferrer i Bigné (València, 1836 / València, 1892) i Jacint Labaila González (València, 1833 / València, 1895).

En aquest certamen literari, Querol es refereix a la llengua catalana com a «natiu idioma» i brinda «perquè, quan tornen de maig les roses noves / pugam cantar, poetes, les catalanes trobes» (Blasco 1988: 45-46). Més tard, l'any 1877 publica a València Rimas, llibre que conté poesies «castellanas» (1877: 23-302) i tres «catalanas» (1877: 304-325) amb la corresponent versió castellana (Ribelles 1978: 519). La decisió de Querol de titular les seues poesies amb el mot «catalanas» serà criticat el mateix 1877 des de les pàgines de Lo Rat-Penat. Calendari Llemosí per Constantí Llombart, màxim defensor del nom «llemosí» per a la llengua. En l'article titulat «Revista de l'any passat» (1877: 1116) Llombart es queixa del poc interés dels valencians per la llengua pròpia, comenta notícies sobre el moviment literari en català al País Valencià i afirma:

\footnotetext{
Lo que sí que no ham pogut compendrer, y debem dirho, es lo motiu per qué lo poeta, tan amant sempre de Valencia, ha tingut l' estrany capritjo de titolarne Rimas catalanas les tres úniques poesíes llemosines qu' estampa, tan notables com tot lo eixit de sa ploma, sent aixina qu’ en llemosina llengua están escrites.

¿Per quína rahó, que nosaltres, Sr. Querol; no hi acertem á explicarnos, denominarles catalanes y no llemosines? No ho entenem, Sr. Querol, no ho entenem. (1877: 13)
}

Ben senzill: perquè el nom científic del conjunt de la llengua era «català» $\mathrm{i}$ «llengua catalana». Ja ho havien dit els iniciadors europeus de la filologia romànica en la primera meitat del segle XIX, de la mateixa manera que en la dècada dels 50 ho afirmen els catalans Bofarull (1854) i Milà i Fontanals (1858 i 1859). Tanmateix, Querol evita contestar públicament a les preguntes de Llombart i, dos anys 
després, torna a ser apel lat -d’una manera més moderada- sobre el títol de les «Rimes catalanes»: en 1877, cedint á les repetides instancies de sos amichs y admiradors, baix lo modest títol de Rimas, reuní y publicá en un volúm en quart (...) ses inapreciables poesíes castellanes (...) / y seguides, ab prou sentiment nostre, de sols tres composicions llemosines, que no sabem per quin fundat motiu lo poeta nomena catalanes. (Llombart 1879: 397-398)

Llombart sabia «per quin fundat motiu» Querol -entre d'altres- anomenaven «català» al conjunt de la llengua catalana. Tanmateix, l'objectiu de Llombart en aquesta qüestió era mantenir l'erroni nom «llemosí» per al conjunt de la llengua catalana. ${ }^{3} \mathrm{Un}$ nom que els filòlegs romànics europeus ja havien bandejat per la confusió que creava.

L'altra reacció que coneixem sobre aquest fet és la que escrigué Teodor Llorente el 1891 en el pròleg de la segona edició de les Rimes de Querol, el qual afirmava que

$$
\begin{aligned}
& \text { con ser tan pocas las poesías que en valenciano escribió, bastaron ellas para su glorificación } \\
& \text { en toda Cataluña. Catalanas las tituló, al incluirlas en su libro, y esta calificación ha parecido } \\
& \text { mal á los que repugnan dar el dictado genérico de lengua catalana á la que comprende, como } \\
& \text { tronco común, las tres ramas: catalana propiamente dicha, valenciana y mallorquina. Cuestión } \\
& \text { de nombre es ésta a la que no doy importancia. (Llorente 1891: xxxiII) }
\end{aligned}
$$

Amb aquestes afirmacions, Llorente tractava de mantenir una certa equidistància entre les opinions enfrontades de Querol i Llombart respecte al nom i l'entitat de la llengua. Ara bé, l'any 1868 Llorente ja havia afirmat nítidament l'entitat independent del conjunt de la llengua catalana i havia admés la impropietat terminològica del mot «llemosí» per a designar el conjunt d'aquesta (MartíBadia 2015). ${ }^{4}$

Al capdavall, Querol feu cas omís a les crítiques de Llombart respecte al nom de les seues «Rimes catalanes», com es desprén del fet que en l'edició pòstuma d'aquestes el 1891 a Madrid les continua titulant així.

Les dades epistolars també revelen molta informació important al respecte. El 1884, en una carta a Llorente, signada a Madrid amb data de 18 de novembre, Querol afirma respecte al discurs que ha de realitzar com a president dels Jocs Florals de Barcelona de 1885: «Ahí es nada escribir un discurso en catalán para los catalanes: cierro los ojos al peligro y jadelante!» (Llorente 1928: 134); encara que més endavant afirma: «Nada me dices de tu tomo de poesías lemosinas», en referència al Llibret de versos de Llorente, que fou publicat l'any següent. Dos mesos més tard, concretament el 6 de gener de 1885, torna a enviar una carta a Llorente en la qual torna a referir-se en els següents termes a l'esmentat discurs: «Aun no he tenido tiempo para pensar en mi discurso de los Juegos Florales. (...) Luego veré si puedo disponer de algún ocio para repasar mi olvidado catalán» (Llorente 1928: 136). Encara que després, en termes semblants a la carta anterior, es refereix així

3 L'opinió de Llombart respecte al nom, l'origen i l'entitat de la llengua catalana -però- mereix un treball monogràfic al respecte. Treball que tenim en projecte.

4 Pel que fa al nom de la llengua, Llorente abandonà progressivament l'ús de «llemosí» i «llengua llemosina» pels noms privatius «valencià» $\mathrm{i}$ «llengua valenciana» $\mathrm{i}$-en menor mesura- pel nom «català» (Roca 2010). 
a l'esmentat llibre de poesies de Llorente: «la próxima publicación de tus poesías lemosinas, que aguardo con ansia, me servirá de mucho para refrescar la imaginación y recordar los olvidados giros de la lengua de oc» (Llorente 1928: 136).

L'any següent Querol realitza l'esmentat «Discurs del Sr. President del Consistori», en el qual es refereix així al recentment traspassat Milà i Fontanals: «Mestre ben aymat y consultat oracle del renaixement llemosí, sembla que al anarsen d'entre nosaltres haja deixat en desvaliment y orfanesa les lletres catalanes» (Roca 2012: 241), ${ }^{5}$ a qui «la erudició ben triada y'l coneixement á fons de totes les literatures neollatines no impedia la realisació de la seua propia obra artística» (Roca 2012: 24142). I més endavant es refereix als Jocs Florals com una: «gran festa anyal de la antiga y forta raça catalana, que congrega fins als més llunyadans parents» (Roca 2012: 242), fent servir el sintagma «raça catalana» en el sentit de pertànyer a la mateixa comunitat de parla que catalans i balears.

A més, com dóna compte Ferrando (2006: 214), mentre era president de l'Ateneu de València hi pronuncia una conferència titulada «Breves consideraciones acerca del renacimiento catalán», en la qual no fa estableix cap diferència entre «llemosí» $\mathrm{i}$ «català».

Tot amb tot, és cert que «caldria tenir en compte si l'atreviment singular de Querol no es veuria facilitat per la llunyania física de València i de les seues pressions» (Simbor 1988: 37), encara que la seua relació amb València és constant i perllongada en el temps. Així, Querol no només «titulà "Rimes catalanes" el recull de poemes renaixencistes que publicà al costat dels poemes en castellà al llibre Rimas, de 1877» (Simbor 1988: 37), sinó que també ho feu a la segona edició d'aquestes (1891) prologada per Llorente i en la conferència a l'Ateneu de València. Com hem vist, Querol empra públicament el mot «catalanes» per a referir-se a les seues poesies i es refereix al renaixement literari del conjunt de les terres de parla catalana amb el sintagma «el renacimiento catalán», i en privat també es refereix al «catalán» com a la llengua en què farà el discurs dels Jocs Florals de 1885. A més, Querol era coneixedor de l'obra filològica de Milà i Fontanals i manté una relació fluïda amb els renaixencistes catalans, fets que també degueren influir sobre la seua posició respecte al nom de la llengua. Tampoc podem deixar de banda el fet que en privat, almenys per carta a Llorente, es refereix amb el mot «llemosines» a les poesies d'aquest darrer, però sembla que es tracta més bé d'una forma de cortesia cap al seu amic Llorente pel fet que aquest preferia emprar el mot «llemosí» per referir-se a la llengua literària.

\subsubsection{Josep Maria Puig i Torralva}

Participa des de ben jove en Lo Rat Penat (1878), entitat on es dóna a conéixer com a poeta. Deixeble de Constantí Llombart, segons aquest escriptor, Torralva era «un poeta genuinament valenciá, l' únich acás que rónegament cultiva nostre idioma» Llombart (1879: 742).

5 Citem el discurs de Roca (2012), que l'ha transcrit recentment en la seua totalitat. 
Obtingué l'accèssit als Jocs Florals de València amb Ensaig d'Ortografia valenciana, tema que fou proposat per l'«Ateneu lliterari de Valencia» (Llombart 1879: 742). És ben probable que aquesta obra continga informació d'interés entorn al nom i l'entitat de la llengua catalana. Lamentablement, però, no se’n conserva cap exemplar en l'actualitat i l'única notícia que tenim és que «tenía en preparación para darlas a la estampa, al tiempo de ocurrir su fallecimiento» (Ribelles 1978: 516).

El 1880 Puig i Torralva continua la tasca -iniciada l'any 1874 per Llombart-d'edició i direcció de la revista Lo Rat-Penat. Calendari Llemosí. A l'article inicial d'aquest exemplar, Torralva fa referència al «renaiximent lliterari del idioma patri» (1880:12) i publica un article de l'escriptor català Ignasi Ferrer i Carrió (Barcelona, 1848 / Barcelona, 1903) titulat «Gramática histórica de la llengua catalana». En aquest, Ferrer i Carrió afirma la necessitat d’una gramàtica històrica «que donará llum corresponent pera apreciar á la vegada la procedencia de la llengua y la fidel construcció de / la mateixa» (1880: 88-89), «la llengua catalana (...) [i] las brancas que d'ella han naxcut (la valenciana y la mallorquina)» (1880: 89). En aquest sentit, considerem que la direcció de la revista assumeix els postulats dels articles a l'hora de publicar-los o -almenys- no els rebutja. També s'hi publica el poema «Morir d'amon» que l'escriptor valencià Francesc Fayos i Antoni (València, 1848 / Barcelona, 1904) -de Barcelona estant- dedica «a mon bon amic lo entusiasta catalanista y llorejat poeta valencià En Josep M. Puig» Torralva (1880: 31).

L'any següent publica un article sobre Llombart a Lo Rat-Penat. Calendari Llemosí, en el qual realitza l'afirmació més contundent que li coneixem actualment sobre el nom de la llengua catalana. Concretament, afirma que Llombart,

com tots los poetes valencians, apellida llemosina á sa llengua nativa. Nosaltres, sobre este punt, som de molt distinta opinió; puix creem firmement, y d' aixó nos ocuparem ab lo degut deteniment en altra part, que la llengua del Turia, com la del Llobregat, es catalana. (1881: 145)

Però no arriba a ocupar-se «ab lo degut deteniment en altra part», o -almenys- eixe treball encara no l'ha exhumat cap investigador. Tanmateix, la posició de Puig i Torralva, evoluciona cap a les posicions «llemosinistes» de Llombart, ben probablement per la seua progressiva proximitat a Llombart i a la contundència amb què aquest darrer va defensar la seua posició. ${ }^{6}$

\section{Conclusions}

Comptat i debatut, els erudits valencians Benvingut Oliver i Joan Baptista Perales són partidaris d'emprar el mot «català»-i «llengua catalana»- per a referir-se al conjunt de la llengua catalana, en consonància amb els postulats de la incipient filologia romànica. Aquesta posició fou minoritària entre els escriptors i erudits valencians de l'època, sobretot si la comparem amb la posició

6 L'any 1883 és guardonat als Jocs Florals de València per la seua obra -en català- Historia gramatical de la lengua lemosino-valenciana, en què empra el sintagma «llemosino-valenciana» per a la llengua catalana del País Valencià i «llemosino-catalana» per a la llengua catalana de Catalunya. De fet, Rafanell (1991: 48) es pregunta: «¿No era aquest mateix Puig Torralva qui, un any abans, havia publicat que la llengua del Túria era, literalment "catalana"?». SCRIPTA, Revista internacional de literatura i cultura medieval i moderna, núm. 6 / desembre 2015 / pp. 120 - 135 ISSN: 2340-4841 · doi:10.7203/SCRIPTA.6.7827 
Adrià Martí i Badia. La llengua dels valencians en l’obra de Benvingut Oliver i Joan Baptista Perales

llemosinista. Però també hem vist com Querol no fou l'únic que la va emprar, ${ }^{7}$ si no que en aquest posició també trobem -almenys-a Benvingut Oliver, Joan B. Perales i Josep M. Puig -en la seua joventut.

Tanmateix, Oliver i Perales encara no havien superat la creença -errònia- de l'origen independent -i deslligat- de la llengua catalana respecte de l'occitana. Una confusió encara estesa entre els erudits del conjunt dels territoris de parla catalana. En tot cas, cal tindre en compte la llunyania física d'Oliver i Perales de la ciutat de València i de l'entitat Lo Rat Penat, on el llemosinisme era àmpliament majoritari perquè no entrava en conflicte amb els sentiments identitaris dels escriptors $i$ erudits valencians de l'època.

7 Creença estesa amb afirmacions com la de Simbor (1988: 37), segons la qual, «l'única excepció fou Querol, que titulà «Rimes catalanes» el recull de poemes [...]. De totes maneres fou un cas únic». 
Adrià Martí i Badia. La llengua dels valencians en l'obra de Benvingut Oliver i Joan Baptista Perales

\section{Bibliografia}

Archilés, F. (2007) “La Renaixença al País Valencià i la construcció de la identitat regional”, Anuari Verdaguer 15, pp. 483-519.

Badia i Margarit, A. M. (1989) "Presència internacional de la llengua catalana", dins Ferrando, A. (ed.) Segon Congrés Internacional de la llengua catalana, vol. vIII, València / Barcelona, IFV / PAM, pp. 3-18.

Bernat i Baltrons, F. (2010) "La relació entre el català i l'occità a l'obra de Manuel Milà i Fontanals", dins Actes del Catorzè Col Loqui Internacional de Llengua i Literatura Catalanes, vol. III, Barcelona, Publicacions de l'Abadia de Montserrat, pp. 85-95.

Blasco, R. (1988) "Llengua i pàtria al País Valencià durant la Renaixença”, Caplletra 4, p. 43-67.

Bofarull, A. de (1854) “La lengua catalana”, Diario de Barcelona 1-8-1854, pp. 5506-5508.

Colón, G. (1978) “Llemosí i llengua d’oc a la Catalunya medieval”, dins La llengua catalana en els seus textos, vol. I, Barcelona, Curial, pp. 39-59.

Cucó, A. (1999 [1a ed. 1971]) El valencianisme politic 1874-1939, Catarroja, Afers.

Fayos, F. (1880) "Morir d'amor", Lo Rat-Penat. Calendari Llemosí corresponent al present any 1881, pp. 31-32.

Ferrando, A. (2006) "Percepció i institucionalització de la norma lingüística entre els valencians: panorama històric (1238-1976)", dins Ferrando, A. / Nicolás, N. (eds.) La configuració social de la norma lingüistica a l'Europa llatina, Alacant, Institut Interuniversitari de Filologia Valenciana, pp. 189-251.

Ferrer i Carrió, I. (1880) “Gramática histórica de la llengua catalana”, Lo Rat-Penat. Calendari Llemosí corresponent al present any 1881, pp. 88-90.

Fuster, J. (1982) País Valencià, per què?, València, Tres i Quatre.

- (1979) Destinat (sobretot) a valencians, València, Eliseu Climent.

Llombart, C. (1879) Los fills de la morta-viva. Apunts bio-bibliográfichs per a la bistoria del renaiximent lliterari llemosí, València, Emili Pasqual.

— (1877) "Revista de l'any passat", Lo Rat-Penat. Calendari Llemosí corresponent al present any 1878, pp. $11-16$.

Llorente, T. (1928) Epistolari Llorente, vol. I, Barcelona, Biblioteca Balmes.

— (1891) "Prologo", dins Querol, Vicent V., Rimas, Madrid, Imprenta de Manuel Tello, pp. viI-XLIV.

Marcet, P. i Solà, J. (1998) Història de la lingüística catalana (1775-1900). Repertori crític, 2 vol., Girona / Vic, Universitat de Girona / Eumo. 
Adrià Martí i Badia. La llengua dels valencians en l'obra de Benvingut Oliver i Joan Baptista Perales

Martí-Badia, A. (2015) "La posició dels renaixencistes valencians davant els postulats de la filologia romànica sobre el valencià", dins Actes del XVIIѐ Col loqui Internacional de Llengua i Literatura Catalanes. AILLC (València, 7-10 juliol 2015), Web, <http://ocs.uv.es/ index.php/AILLC>, En premsa.

Oliver i Estellés, B. (1881) Historia del derecho en Cataluña, Mallorca y Valencia, vol. IV, Madrid, Imprenta de Miguel Ginesta.

- (1876) Historia del derecho en Cataluña, Mallorca y Valencia, vol. I, Madrid, Imprenta de Miguel Ginesta.

Perales, J. B. (1880) Décadas de la historia de la insigne y coronada ciudady reino de Valencia, vol. III, Valencia / Madrid, Terraza, Aliena y Compañia editores.

Puig i Torralva, J. M. (1881) "En Constantí Llombart. Apunts biografichs", Lo Rat-Penat. Calendari Llemosi corresponent al present any 1882, València, pp. 145-147.

- (1880) "Revista del passat any", Lo Rat-Penat. Calendari Llemosí corresponent al present any 1881, pp. $12-16$.

Querol, V. V. (1877) Rimas, València, Imprenta de J. Domenech.

- (1891) Rimas, Madrid, Imprenta de Manuel Tello.

Rafanell, A. (1991) "El llemosinisme valencià a la darreria del segle xix", Caplletra 11, pp. 35-50.

Ribelles, J. (1978) Bibliografía de la lengua valenciana. vol. 4, Madrid, Servicio de Publicaciones del Ministerio de Educación y Ciencia.

Roca, R. (2012) "Valencians als jocs florals de Barcelona (1862-1893)" dins Domingo, J. M. (ed.) Joc literari $i$ estratègies de representació. 150 anys dels Jocs Florals de Barcelona, Barcelona, Institut d'Estudis Catalans / Societat Catalana de Llengua i Literatura, pp. 199-247.

- (2010) “Teodor Llorente i la llengua dels valencians”, Caplletra 49, pp. 43-63.

Simbor, V. (1988) “La Renaixença al País Valencià”, Caplletra 4, pp. 9-44. 